\title{
Whole-exome sequencing in patients with premature ovarian insufficiency: early detection and early intervention
}

Hongli Liu ${ }^{1 \dagger}$, Xiaoli Wei ${ }^{2 \dagger}$, Yanwei Sha ${ }^{3+}$, Wensheng Liư ${ }^{4}$, Haijie Gao ${ }^{3}$, Jin Lin ${ }^{3}$, Youzhu Li ${ }^{5}$, Yaling Tang ${ }^{6}$, Yifeng Wang ${ }^{4^{*}}$, Yanlong Wang ${ }^{1 *}$ and Zhiying $\mathrm{Su}^{3^{*}}$ (1)

\begin{abstract}
Background: The loss of ovarian function in women, referred to as premature ovarian insufficiency (POI), is associated with a series of concomitant diseases. POI is genetically heterogeneous, and in most cases, the etiology is unknown.

Methods: Whole-exome sequencing (WES) was performed on DNA samples obtained from patients with POI, and Sanger sequencing was used to validate the detected potentially pathogenic variants. An in silico analysis was carried out to predict the pathogenicity of the variants.

Results: We recruited 24 patients with $\mathrm{POI}$ and identified variants in POI-related genes in 14 patients, including biallelic mutations in DNAH6, HFM1, EIF2B2, BNC, and LRPPRC and heterozygous variants in BNC1, EIF2B4, FOXL2, MCM9, FANCA, ATM, EIF2B3, and GHR. No variants in the above genes were detected in the WES data obtained from 29 women in a control group without POI. Determining a clear genetic etiology could significantly increase patient compliance with appropriate intervention strategies.

Conclusions: Our study confirmed that POI is a genetically heterogeneous condition and that whole-exome sequencing is a powerful tool for determining its genetic etiology. The results of this study will aid researchers and clinicians in genetic counseling and suggests the potential of WES for the detection of POI and thus early interventions for patients with POI.
\end{abstract}

Keywords: Premature ovarian insufficiency, Pathogenic variants, Whole-exome sequencing, Early intervention, Compliance

\footnotetext{
*Correspondence: yifengw1981@126.com; xmfy_wyl@126.com; xmfyszy@163.com

${ }^{+}$Hongli Liu, Xiaoli Wei and Yanwei Sha contributed equally to this work. ${ }^{4}$ Department of Gynecology and Obstetrics, Zhujiang Hospital, Southern Medical University, Guangzhou 510000, Guangdong, China

'Department of Gynecology, Key Clinical Discipline of Fujian province, Women and Children's Hospital, School of Medicine, Xiamen University, Xiamen 361005, Fujian, China

${ }^{3}$ Department of Reproductive Medicine, Women and Children's Hospital, School of Medicine, Xiamen University, Xiamen 361005, Fujian, China

Full list of author information is available at the end of the article
}

(c) The Author(s). 2020 Open Access This article is licensed under a Creative Commons Attribution 4.0 International License, which permits use, sharing, adaptation, distribution and reproduction in any medium or format, as long as you give appropriate credit to the original author(s) and the source, provide a link to the Creative Commons licence, and indicate if changes were made. The images or other third party material in this article are included in the article's Creative Commons licence, unless indicated otherwise in a credit line to the material. If material is not included in the article's Creative Commons licence and your intended use is not permitted by statutory regulation or exceeds the permitted use, you will need to obtain permission directly from the copyright holder. To view a copy of this licence, visit http://creativecommons.org/licenses/by/4.0/ The Creative Commons Public Domain Dedication waiver (http://creativecommons.org/publicdomain/zero/1.0/) applies to the data made available in this article, unless otherwise stated in a credit line to the data. 


\section{Background}

Premature ovarian insufficiency (POI) is defined as amenorrhea before the age of 40 and is characterized by FSH levels greater than $25 \mathrm{IU} / \mathrm{L}$ in two measurements for at least 4 weeks [1]. POI is a severe disorder affecting approximately $1 \%$ of women of childbearing age worldwide [2]. Genetic defects are a common cause of POI, as has been proven in a large number of studies. Currently, with the development of technology, more than 100 genes have been found to be associated with POI [3-6].

Whole-exome sequencing (WES) is widely used to identify the genetic etiologies of various diseases [7]. However, gynecologists diagnose and treat POI only based on a patient's symptoms, and genetic methods have not been widely used to identify the genetic causative factors of idiopathic POI. With the significant decrease in the price of WES, it has emerged as a powerful tool with potential for clinical applications in the early detection of POI and timely intervention for patients with POI. Moreover, a clear genetic etiology could significantly improve treatment compliance.

In this study, we performed WES of DNA samples obtained from 24 patients with POI and found variants in POI-related genes in 14 patients. Therefore, it is possible to conduct etiological testing for patients with POI through WES, which could help in the timely intervention of POI.

\section{Results}

\section{Clinical features of patients with $\mathrm{POI}$}

All 24 patients were diagnosed with sporadic POI according to standard criteria (detailed in the Methods section). Based on the physical examination results, none of the patients showed an obvious abnormality in physical development. The ovaries of all patients could be detected by transvaginal color Doppler ultrasound examination. However, all patients had abnormal hormone levels. All patients with POI had a normal 46, XX karyotype. The clinical characteristics of the POI patients are shown in Table 1.

\section{Whole-exome sequencing analysis of patients with premature ovarian insufficiency}

To characterize the genetic pathogenesis of POI, we performed WES of the DNA samples of the 24 POI patients. We retained the variants with a minor allele frequency of less than $1 \%$ in the dbSNP, 1000G, ESP6500, and gnomAD databases. The retained variants were filtered according to the selected candidate genes involved in POI. We identified 19 variants in 12 genes, including compound heterozygous variants in DNAH6, $H F M 1, E I F 2 B 2, B N C 1$, and LRPPRC and nine heterozygous variants in $B N C 1, E I F 2 B 4, F O X L 2, M C M 9$, $F A N C A, A T M, E I F 2 B 3$, and GHR, from 14 patients (Table 2). None of the above genes were detected in the WES data from 29 women in the control group.

Sanger sequencing was performed on samples from a subset of patients (POI-1, 3, and 6-9) and their family members to validate the variants and investigate inheritance. POI-1 harbored two compound heterozygous variants in DNAH6, c.2407C $>\mathrm{A}$ and c.8680G $>\mathrm{A}$. Her unaffected mother carried the heterozygous variant c. $2407 \mathrm{C}>\mathrm{A}$, and her father carried the heterozygous

Table 1 Clinical and hormonal characteristics of the patients with POI

\begin{tabular}{|c|c|c|c|c|c|c|c|c|c|c|}
\hline Case ID & Age (Years) & $\begin{array}{l}\text { Menopause } \\
\text { age (Years) }\end{array}$ & BMI (kg/m2) & $\begin{array}{l}\text { Primary or } \\
\text { secondary } \\
\text { amenorrhea }\end{array}$ & FSH (IU/L) & LH (IU/L) & E2 (pg/mL) & Karyotype & $\begin{array}{l}\text { Ovary size } \\
\text { (right/ left, mm) }\end{array}$ & Follicle \\
\hline POI-1 & 35 & 33 & 25.20 & secondary & 35.92 & 16.61 & 24 & $46, X X$ & $21 * 16 / 22 * 18$ & Rare \\
\hline $\mathrm{POI}-3$ & 29 & 27 & 28.25 & secondary & 161.18 & 56.92 & 21 & $46, X X$ & $18^{*} 11 / 16^{*} 11$ & Absent \\
\hline POI-6 & 30 & 28 & 24.14 & secondary & 73.77 & 27.56 & 79 & $46, X X$ & $19 * 11 / 18^{*} 12$ & Absent \\
\hline POI-7 & 23 & 13 & 23.80 & primary & 127.54 & 39.5 & 34 & $46, X X$ & $15^{*} 10 / 13^{*} 9$ & Absent \\
\hline POI-8 & 25 & 15 & 25.71 & primary & 92.93 & 43.38 & 13 & $46, X X$ & $10^{*} 6 / 11 * 5$ & Absent \\
\hline POI-9 & 24 & 18 & 25.46 & secondary & 102.8 & 38.39 & 20 & $46, X X$ & $18 * 9 / 21 * 8$ & Absent \\
\hline POl-11 & 32 & 31 & 22.31 & secondary & 48.65 & 40.24 & 18 & $46, X X$ & $19 * 12 / 17^{*} 15$ & Rare \\
\hline POI-12 & 28 & 27 & 25.65 & secondary & 86.57 & 35.77 & 22 & $46, X X$ & $16^{*} 11 / 15^{*} 9$ & Rare \\
\hline POl-14 & 30 & 28 & 22.83 & secondary & 110.38 & 51.60 & 16 & $46, X X$ & $17^{*} 14 / 16^{*} 10$ & Absent \\
\hline POl-17 & 25 & 24 & 22.86 & secondary & 55.24 & 36.83 & 15 & $46, X X$ & $20 * 14 / 21^{*} 17$ & Rare \\
\hline POl-18 & 27 & 26 & 27.55 & secondary & 60.45 & 50.46 & 18 & $46, X X$ & $18^{*} 10 / 17^{*} 8$ & Rare \\
\hline POI-21 & 22 & 14 & 23.07 & primary & 107.28 & 38.55 & 24 & $46, X X$ & $11 * 6 / 12 * 5$ & Absent \\
\hline POI-23 & 26 & 25 & 25.81 & secondary & 38.50 & 24.69 & 15 & $46, X X$ & $17^{*} 15 / 16^{*} 13$ & Rare \\
\hline POI-24 & 16 & 13 & 24.31 & primary & 49.66 & 35.52 & 33 & $46, X X$ & $10 * 5 / 11 * 4$ & Absent \\
\hline
\end{tabular}

Abbreviation: FSH Follicle-stimulating hormone, LH Luteinizing hormone, E2 Estradiol 
Table 2 In silico analysis of variants found by whole-exome sequencing

\begin{tabular}{|c|c|c|c|c|c|c|c|c|}
\hline $\begin{array}{l}\text { Case } \\
\text { ID }\end{array}$ & Zygosity & Gene & Ref mRNA No. & $\begin{array}{l}\text { Mutation } \\
\text { type }\end{array}$ & Variants & $\begin{array}{l}\text { Amino acid } \\
\text { change }\end{array}$ & gnomAD & $\begin{array}{l}\text { PolyPhen/SIFT/ } \\
\text { MutationTaster/CADD/DANN }\end{array}$ \\
\hline \multirow[t]{2}{*}{ POI-1 } & Het. & \multirow[t]{2}{*}{ DNAH6 } & \multirow[t]{2}{*}{ NM_001370.2 } & missense & c. $2407 C>A$ & p.Q803K & 0.000004062 & $\mathrm{~B} / \mathrm{T} / \mathrm{P} / \mathrm{T} / \mathrm{T}$ \\
\hline & Het. & & & missense & $c .8680 G>A$ & p.V2894M & 0 & D/D/D/D/D \\
\hline POI-3 & Het. & $B N C 1$ & NM_001717.4 & missense & c. $1724 \mathrm{~A}>\mathrm{T}$ & p.D575V & 0.0003 & D/T/D/D/D \\
\hline \multirow[t]{2}{*}{ POI-6 } & Het. & \multirow[t]{2}{*}{ HFM1 } & \multirow{2}{*}{$\begin{array}{l}\mathrm{NM}_{-} \\
001017975.6\end{array}$} & missense & c.3100G > A & p.G1034S & 0 & D/D/D/D/D \\
\hline & Het. & & & splice-site & $\begin{array}{l}\text { c. } 1006+1 G> \\
T\end{array}$ & - & 0.00000523 & $-/-/ D / D / D$ \\
\hline POI-7 & Het. & EIF2B4 & NM_015636.3 & missense & c.1397G > A & p.R466Q & 0.00007716 & D/T/D/D/D \\
\hline POI-8 & Het. & FOXL2 & NM_023067.4 & missense & c. $676 \mathrm{G}>\mathrm{A}$ & p.A226T & 0 & D/D/P/D/D \\
\hline POI-9 & Het. & MCM9 & NM_017696.3 & missense & c. $2488 \mathrm{G}>\mathrm{A}$ & p.A830T & 0.00002173 & $\mathrm{~B} / \mathrm{T} / \mathrm{P} / \mathrm{T} / \mathrm{T}$ \\
\hline POI-11 & Het. & FANCA & NM_000135.4 & missense & c.2340T > G & p.H780Q & 0 & $\mathrm{D} / \mathrm{D} / \mathrm{P} / \mathrm{T} / \mathrm{T}$ \\
\hline POI-12 & Het. & ATM & NM_000051.4 & missense & c. $2367 C>$ G & p.N789K & 0 & $\mathrm{~B} / \mathrm{T} / \mathrm{P} / \mathrm{T} / \mathrm{T}$ \\
\hline \multirow[t]{2}{*}{ POI-14 } & \multirow[t]{2}{*}{ Het. } & \multirow[t]{2}{*}{ EIF2B2 } & \multirow[t]{2}{*}{ NM_014239.4 } & \multirow[t]{2}{*}{ missense } & $c .76 \mathrm{G}>\mathrm{A}$ & p.G26S & 0.000008134 & D/T/D/T/D \\
\hline & & & & & $c .922 \mathrm{G}>\mathrm{A}$ & p.V308M & 0.000008122 & D/D/D/D/D \\
\hline POI-17 & Het. & EIF2B3 & NM_020365.5 & missense & c.389T > C & p.M130T & 0.00003656 & $\mathrm{~B} / \mathrm{T} / \mathrm{D} / \mathrm{D} / \mathrm{T}$ \\
\hline POI-18 & Het. & FOXL2 & NM_023067.4 & missense & C. $118 \mathrm{G}>\mathrm{C}$ & c.G118C & 0.00001754 & $\mathrm{D} / \mathrm{T} / \mathrm{P} / \mathrm{T} / \mathrm{D}$ \\
\hline \multirow[t]{2}{*}{ POI-21 } & \multirow[t]{2}{*}{ Het. } & \multirow[t]{2}{*}{$B N C 1$} & \multirow[t]{2}{*}{ NM_001717.4 } & missense & c. $1703 \mathrm{~A}>\mathrm{T}$ & p.D568V & 0.0003 & D/T/D/D/D \\
\hline & & & & missense & c.1574T > C & p.L525P & 0.0006 & D/D/D/D/D \\
\hline POI-23 & Het. & GHR & NM_000163.5 & missense & $c .282 G>A$ & p.W94X & 0 & $-/-/ D / D / T$ \\
\hline \multirow[t]{2}{*}{ POI-24 } & \multirow[t]{2}{*}{ Het. } & \multirow{2}{*}{$\begin{array}{l}\angle R P P \\
R C\end{array}$} & \multirow[t]{2}{*}{ NM_133259.4 } & \multirow[t]{2}{*}{ missense } & $c .7 \mathrm{G}>\mathrm{T}$ & p.A3S & 0.0001 & D/D/D/D/D \\
\hline & & & & & c.2965C > T & p.R989C & 0.0005 & D/D/D/D/D \\
\hline
\end{tabular}

Abbreviation: PolyPhen http://genetics.bwh.harvard.edu/pph2/. D: Probably damaging (>=0.957), P: possibly damaging (0.453<=pp2_hdiv<=0.956) B: benign (pp2_hdiv<=0.452), SIFT http://sift.bii.a-star.edu.sg/. D: Deleterious (sift<=0.05); T: tolerated (sift> 0.05), MutationTaster http://www.mutationtaster.org/. A" ("disease_causing_automatic"); “D” ("disease_causing"); “N" ("polymorphism"); “P” ("polymorphism_automatic", CADD https://cadd.gs.washington.edu/download. D: Damaging; T: Tolerable, DANN https://cbcl.ics.uci.edu/public_data/DANN/. D: Damaging; T: Tolerable

variant c.8680G > A, indicating that the two variants in POI-1 were inherited, one each, from her parents (Fig. 1a). Compound heterozygous variants c.3100G > A and c.1006 + 1G > T of HFM1 were confirmed in POI-6. The heterozygous c.3100G > A variant was identified in her mother, and the heterozygous c. $1006+1 G>T$ variant was identified in her father (Fig. 1c). Heterozygous variants c.1724A > T in BNC1 (Fig. 1b), c.1397G > A in EIF2B4 (Fig. 1d), c.676G $>\mathrm{A}$ in FOXL2 (Fig. 1e), and c.2488G > A in MCM9 (Fig. 1f) were identified in POI patients and their fathers. Moreover, as expected, the mothers of these four patients harbored wild-type alleles.

\section{Analysis of the novel variants identified in patients with POI}

We evaluated the 19 variants by in-silico analysis. First, we assessed the frequency of the variants. Data from the gnomAD database, a rich and informative database containing exome data from the ExAc and 1000G databases, in addition to data from many other databases, suggest that all of these variants were rare, and six of them were not present in the database. These results indicate that the frequency of these variants in the population is extremely low, which is compatible with the incidence of POI. Moreover, 16 of the 19 variants were predicted to be deleterious by five prediction tools, Polyphen-2, SIFT, MutationTaster, CADD, and DANN (Table 2).

\section{Discussion}

In this study, we performed WES of the DNA samples of 24 POI patients and identified pathogenic variants associated with POI in 14 of the patients. Our study further supports the notion that genetic variants of several genes are important in the pathogenesis of POI and may be the main reason for sporadic cases of unknown etiology.

Previous studies have shown that dynein axonemal heavy chain 6 (DNAH6) is involved in generating the force required for ciliary beating, and mutations in this gene may cause primary ciliary dyskinesia, nonobstructive azoospermia, or sperm morphological defects [8-11]. By using a high-resolution array comparative genomic hybridization platform, a $171 \mathrm{~kb}$ deletion in DNAH6 was identified as the main etiology of POI in a patient [12]. POI-1 harbored two compound heterozygous DNAH6 variants, c. $2407 \mathrm{C}>\mathrm{A}$ and c.8680G $>\mathrm{A}$. 


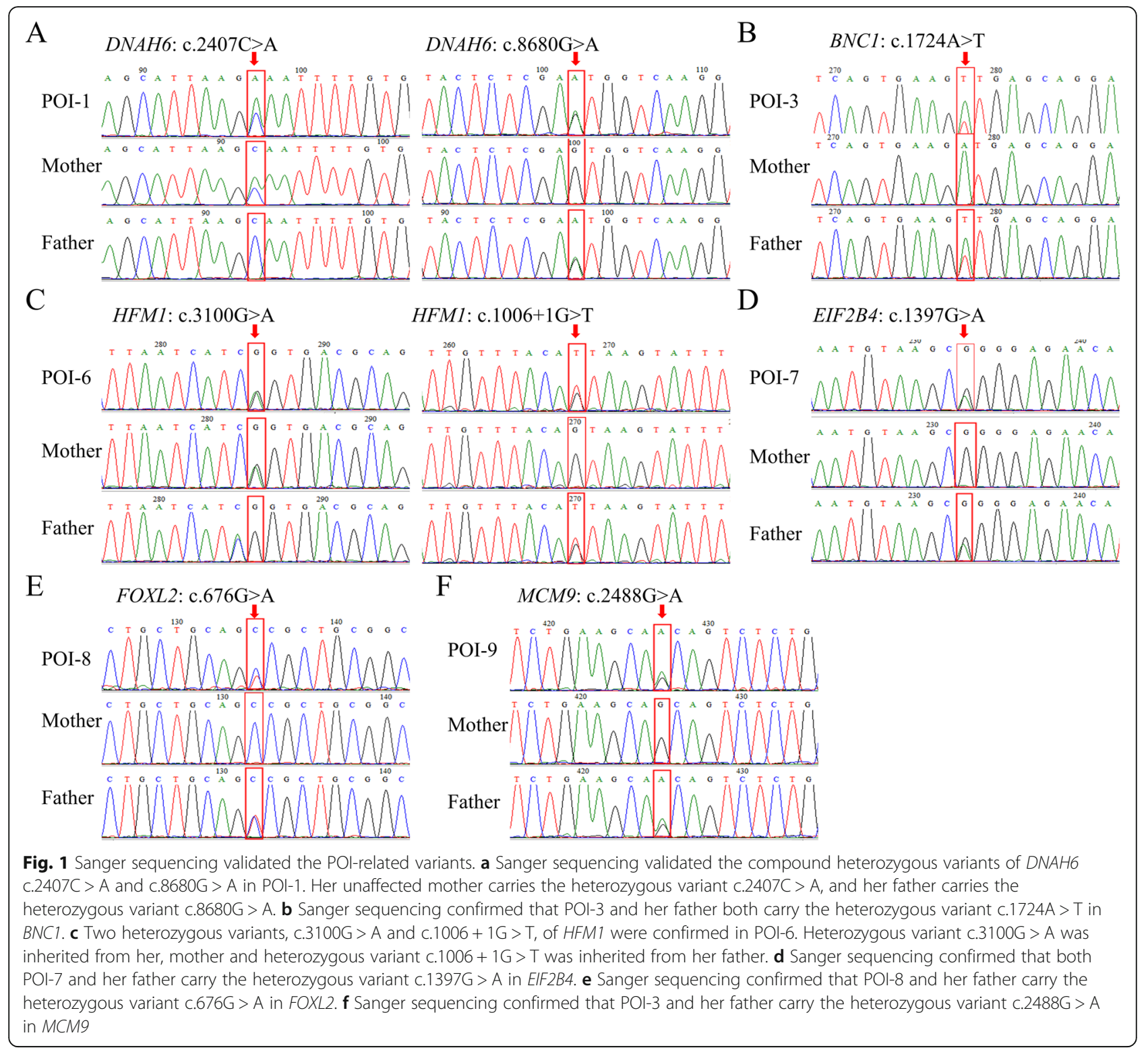

Therefore, DNAH6 is an attractive candidate pathogenic gene for POI.

Basonuclin 1 (BNC1), a zinc finger protein, is abundant in the germ cells of the testis and ovary. BNC1 plays a regulatory role in rRNA transcription during mouse oogenesis, and deletion of the gene (BNC1) that expresses BNC1 protein in mice leads to female subfertility, suggesting that $\mathrm{BNC1}$ is essential for oogenesis [1315]. Haploinsufficiency of $B N C 1$ has been reported as an etiology of human autosomal dominant POI [16]. Another study found a $1597.8 \mathrm{~kb}$ deletion in $B N C 1$ in a patient with POI [17]. POI-3 carried the heterozygous $B N C 1$ variant c. $1724 \mathrm{~A}>\mathrm{T}$, and $\mathrm{POI}-21$ carried the biallelic BNC1variants c.1703A $>\mathrm{T}$ and c. $1574 \mathrm{~T}>\mathrm{C}$. All three variants were predicted to be disease-causing substitutions. In general, both heterozygous and complex heterozygous mutations in $B N C 1$ are pathogenic factors for POI, so it is important to pay particular attention to haploinsufficiency caused by heterozygous mutations.

Helicase for meiosis 1 (HFM1) is an ATP-dependent DNA helicase that is mainly expressed in germ-line cells. Defects in the gene HFM1 cause premature ovarian failure [18-21]. POI-6 harbored the compound heterozygous variants c. $3100 \mathrm{G}>\mathrm{A}$ and c. $1006+1 \mathrm{G}>\mathrm{T}$. Both variants were rare and were predicted to be disease causing. Thus, we suspected that these variants are the main pathogenic determinants in POI-6. 
Eukaryotic translation initiation factor 2B (eIF2B), a multi-subunit protein comprising two sets of $\alpha, \beta, \gamma, \delta$, and $\varepsilon$ subunits, is a guanine nucleotide exchange factor (GEF) specific for eIF2 and a key regulator of mRNA translation. EIF2B2, EIF2B3, and EIF2B4 are the $\beta, \gamma$, and $\delta$ subunits of EIF2B, respectively. All three participate in protein synthesis and exchange GDP and GTP for activation and deactivation [22]. Compound heterozygous variants in EIF2B2 have been identified as a cause of POI in one of four patients by next-generation sequencing [23]. The c.1117C > T (p.Arg373Cys) variant in EIF2B4 was shown to be associated with premature ovarian failure in two patients at the ages of 13 and 18 years, respectively $[24,25]$. POI-14 carried bi-allelic c.76G > A and c.922G > A EIF2B2 variants. POI-17 carried a heterozygous EIF2B3 variant, c.389 T $>C$, and POI-7 carried the EIF2B4 heterozygous variant c.1397G > A. In women of childbearing age with mutations in eIF2B family genes, special attention should be paid to the possibility of POI.

Leucine-rich pentatricopeptide repeat containing (LRPPRC) protein is a leucine-rich protein with a number of pentatricopeptide repeats. This protein plays multiple roles in cytoskeletal organization, vesicular transport, and transcriptional regulation of both nuclear and mitochondrial genes [26]. Mutations in $L R P P R C$ are associated with the French-Canadian type of Leigh syndrome. Surviving females exhibit premature ovarian failure, absent or arrested breast development, a lack of menarche, high follicle-stimulating hormone level, a prepubertal uterus, and small ovaries [27]. POI-24 carried c.7G $>\mathrm{T}$ and c. $2965 \mathrm{C}>\mathrm{T}$ biallelic mutations in $L R P P R C$ and suffered from primary amenorrhea.

Forkhead box L2 (FOXL2, OMIM: 605597) is a forkhead transcription factor that contains a fork-head DNA-binding domain and plays a role in ovarian development and function [28, 29]. Mutations in FOXL2 are known to cause autosomal dominant POI [30-34]. POI-8 harbored a novel heterozygous c.676G $>\mathrm{A}$ variant in FOXL2, which has not been reported previously.

MCM9 is a member of the mini-chromosome maintenance (MCM) protein family, which is essential for the initiation of eukaryotic genome replication and renewal of germ-line stem cells [35]. Bi-allelic mutations in MCM9 cause POI in an autosomal recessive manner [36-38]. Heterozygous variants of MCM9 cause haploinsufficiency and contribute to the pathogenesis of POI, especially secondary amenorrhea [39]. POI-9 carried a heterozygous MCM9 variant, c.2488G > A, and suffered from secondary amenorrhea.

FANCA is a Fanconi anemia complementation group (FANC) protein. Two heterozygous variants in FANCA were identified in two unrelated POI patients from a group of 50 Han Chinese patients with POI by WES [40]. These heterozygous variants reduced FANCA expression levels, and $\mathrm{Fanca}^{+/-}$female mice showed decreased numbers of follicles with aging [40]. POI-11, who carried a heterozygous c. $2340 \mathrm{~T}>\mathrm{G}$ variant in FANCA, was married at 30 years of age and had secondary amenorrhea and POI when trying to conceive.

ATM is a serine/threonine kinase belonging to the PI3/PI4-kinase family. It is a cell cycle checkpoint kinase that plays a crucial role in cell cycle checkpoint signaling pathways, which are required for the cellular response to DNA damage and genome stability [41]. ATM is involved in ovarian function, and ATM deficiency can induce premature ovarian failure [42]. The gonads of patients with ATM defects are hypoplastic with germ cell deficiencies [43]. Deletion of the atm locus in mice accelerated primordial follicle degradation at prophase of meiosis I during oogenesis, leading to primordial and maturing follicles and oocyte deficiency [44]. POI-12 carried the heterozygous $A T M$ variant c. $2367 \mathrm{C}>\mathrm{G}$ and had secondary amenorrhea and POI.

Growth hormone receptor (GHR) is a transmembrane receptor for growth hormone. It binds to $\mathrm{GH}$ and undergoes conformational changes, which eventually result in activation of the JAK2/STAT-5/IGF-I signaling pathway [45]. The litter size of GHR-knockout mice was significantly reduced due to ovarian defects [46]. POI-23 carried a heterozygous $G H R$ variant, c. $282 \mathrm{G}>\mathrm{A}$, and had secondary amenorrhea. We predicted that the ovarian function of this patient was affected by haploinsufficiency.

WES is an unbiased genetic approach that has advantages for identifying the genetic etiologies of POI in patients without obvious somatic anomalies [4750]. In addition to identifying the genetic pathogenesis of patients with unexplained POI, WES also shows broad potential for applications in the screening and early diagnosis of patients with POI. POI patients suffer both mentally and physically due to poor treatment outcomes and unclear etiologies. Clear genetic etiologies will allow us to develop more effective treatment strategies and significantly improve patient compliance.

POI has major impacts on the reproductive ability and physical and mental health of affected patients. Hormone replacement therapy can partially relieve the symptoms induced by POI. However, there are limited effective treatments for the associated impaired reproductive capacity. Therefore, it is important to recognize POI in patients as early as possible to establish a fertility reserve (e.g., oocyte cryopreservation). With the significant decrease in the price and comprehensive spectrum of pathogenic genes, WES 
has good potential for application in the early detection and intervention of POI.

\section{Conclusions}

In summary, we recruited 24 patients with POI and identified pathogenic variants in 14 of these patients. In approximately $60 \%(14 / 24)$ of the sporadic cases in our study, we were able to identify potentially pathogenic mutations, which shows the utility of WES for determining the genetic pathogenesis of POI. Our research showed that WES is an effective method for identifying the genetic etiology in patients with idiopathic POI, which may offer a theoretical basis for the early detection and intervention in patients with potential idiopathic POI in the future.

\section{Methods}

\section{Patients and control subjects}

We recruited 24 patients with POI for this study. POI was diagnosed if a patient had amenorrhea for at least 4 months under the age of 40 years and two consecutive follicle stimulating hormone (FSH) measurements $>25 \mathrm{IU} / \mathrm{L}$ taken 4 weeks apart [1]. Patients who had significant POI-related risk factors were excluded, including karyotype abnormalities, autoimmune disorders, a history of radiotherapy, chemotherapy, or pelvic surgery, and so on. After the patients provided written informed consent, we performed WES on DNA isolated from the peripheral blood samples of the POI patients to identify any disease-associated variants. All procedures involving human participants were performed in accordance with the standards of the Ethics Committee of the Women and Children's Hospital of Xiamen University, Zhujiang Hospital of Southern Medical University, and the First Affiliated Hospital of Xiamen University, and in accordance with the 1964 Declaration of Helsinki and its later amendments or comparable ethical standards. Written informed consent was obtained from each study participant.

\section{Hormone measurements}

Blood hormone (FSH, LH, and E2) levels were measured using a UniCel DxI 800 immunochemistry analyzer (Beckman Coulter Inc., USA) according to the manufacturer's instructions and requirements.

\section{WES analysis and sanger sequencing validation}

WES was performed as described elsewhere. Variants fulfilling the following criteria were retained: (a) missense, nonsense, frameshift, or splice site variants; (b) allele frequencies $<1 \%$ in the dbSNP (http://www.ncbi. nlm.nih.gov/snp/), 1000 Genomes (http://browser.1 000genomes.org/index.html), ESP6500 (http://evs.gs.
washington.edu/EVS/), and Genome Aggregation Database (gnomAD, http://gnomad.broadinstitute.org/) databases. Sanger sequencing was used to validate the variants found in the WES analysis of the patients and their families.

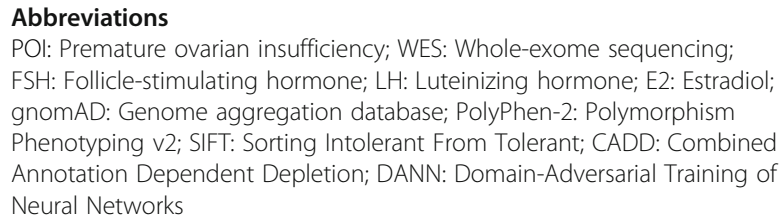

\section{Acknowledgments}

The authors thank all the patients and their family members for their interest and cooperation in the study.

\section{Authors' contributions}

$H L, Y S, Y L$, and $Y T$ collected the clinical samples and performed the clinical diagnosis. XW and WL analysed the WES data and wrote the manuscript. HG and $J$ performed the data analysis. YW, YW, and ZS conceived the study. All authors read and approved the final manuscript.

\section{Funding}

This work was supported by the Fujian Medical Innovation Fund Project (No. 2019-CXB-35) and the Natural Science Foundation of Fujian Province of

China (grant no. 2017 J01361).

\section{Availability of data and materials}

The data underlying the findings of this article will be shared on reasonable request to the corresponding author.

\section{Ethics approval and consent to participate}

The study protocol was performed in accordance with the tenets of the Declaration of Helsinki and was approved by the ethics committees of Women and Children's Hospital of Xiamen University, Zhujiang Hospital of Southern Medical University, and the First Affiliated Hospital of Xiamen University. Written informed consent was obtained from each participant.

Consent for publication

Not applicable.

\section{Competing interests}

The authors declare that they have no competing interests.

\section{Author details}

'Department of Gynecology, Key Clinical Discipline of Fujian province, Women and Children's Hospital, School of Medicine, Xiamen University, Xiamen 361005, Fujian, China. ${ }^{2}$ School of Pharmaceutical Sciences, Xiamen University, Xiamen 361005, Fujian, China. ${ }^{3}$ Department of Reproductive Medicine, Women and Children's Hospital, School of Medicine, Xiamen University, Xiamen 361005, Fujian, China. ${ }^{4}$ Department of Gynecology and Obstetrics, Zhujiang Hospital, Southern Medical University, Guangzhou 510000, Guangdong, China. ${ }^{5}$ Reproductive Medicine Center, the First Affiliated Hospital of Xiamen University, Xiamen 361003, Fujian, China. ${ }^{6}$ Department of Obstetrics and Gynecology, the First Affiliated Hospital of Xiamen University, Xiamen 361003, China.

Received: 23 June 2020 Accepted: 11 September 2020 Published online: 22 September 2020

\section{References}

1. European Society for Human R, Embryology guideline group on POI, Webber L, Davies M, Anderson R, Bartlett J, Braat D, Cartwright B, Cifkova R, de Muinck Keizer-Schrama S, et al. ESHRE guideline: management of women with premature ovarian insufficiency. Hum Reprod. 2016;31(5):926-37.

2. Chae-Kim JJ, Gavrilova-Jordan L. Premature ovarian insufficiency: procreative management and preventive strategies. Biomedicines. 2018;7(1):2. 
3. Qin $Y$, Jiao $X$, Simpson $J$, Chen ZJ. Genetics of primary ovarian insufficiency: new developments and opportunities. Hum Reprod Update. 2015;21(6):787-808.

4. França MM, Mendonca BB. Genetics of primary ovarian insufficiency in the next-generation sequencing era. J Endocr Soc. 2019;4(2):1.

5. Yatsenko SA, Rajkovic A. Genetics of human female infertility. Biol Reprod. 2019;101(3):549-66.

6. Jiao X, Ke H, Qin Y, Chen ZJ. Molecular genetics of premature ovarian insufficiency. Trends Endocrinol Metab. 2018;29(11):795-807.

7. Goh G, Choi M. Application of whole exome sequencing to identify diseasecausing variants in inherited human diseases. Genomics Inform. 2012;10(4): 214-9.

8. Oltean A, Schaffer AJ, Bayly PV, Brody SL. Quantifying Ciliary dynamics during assembly reveals stepwise waveform maturation in airway cells. Am J Respir Cell Mol Biol. 2018;59(4):511-22.

9. Tu C, Nie H, Meng L, Yuan S, He W, Luo A, Li H, Li W, Du J, Lu G, et al. Identification of DNAH6 mutations in infertile men with multiple morphological abnormalities of the sperm flagella. Sci Rep. 2019;9(1):15864.

10. Gershoni M, Hauser R, Yogev L, Lehavi O, Azem F, Yavetz H, Pietrokovski S, Kleiman SE. A familial study of azoospermic men identifies three novel causative mutations in three new human azoospermia genes. Genet Med. 2017;19(9):998-1006.

11. Li L, Sha YW, Xu X, Mei LB, Qiu PP, Ji ZY, Lin SB, Su ZY, Wang C, Yin C, et al. DNAH6 is a novel candidate gene associated with sperm head anomaly. Andrologia. 2018:50(4):e12953.

12. Norling A, Hirschberg AL, Rodriguez-Wallberg KA, Iwarsson E, Wedell A, Barbaro M. Identification of a duplication within the GDF9 gene and novel candidate genes for primary ovarian insufficiency (POI) by a customized high-resolution array comparative genomic hybridization platform. Hum Reprod. 2014;29(8):1818-27.

13. Tseng $H$, Green $H$. Basonuclin: a keratinocyte protein with multiple paired zinc fingers. Proc Natl Acad Sci U S A. 1992;89(21):10311-5.

14. Tian Q, Kopf GS, Brown RS, Tseng H. Function of basonuclin in increasing transcription of the ribosomal RNA genes during mouse oogenesis. Development. 2001;128(3):407-16.

15. Ma J, Zeng F, Schultz RM, Tseng H. Basonuclin: a novel mammalian maternal-effect gene. Development. 2006;133(10):2053-62.

16. Zhang D, Liu Y, Zhang Z, Lv P, Li J, Wu Y, Zhang R, Huang Y, Xu G, Qian Y, et al. Basonuclin 1 deficiency is a cause of primary ovarian insufficiency. Hum Mol Genet. 2018;27(21):3787-800.

17. Tsuiko O, Noukas M, Zilina O, Hensen K, Tapanainen JS, Magi R, Kals M, Kivistik PA, Haller-Kikkatalo K, Salumets A, et al. Copy number variation analysis detects novel candidate genes involved in follicular growth and oocyte maturation in a cohort of premature ovarian failure cases. Hum Reprod. 2016;31(8):1913-25.

18. Wang J, Zhang WX, Jiang H, Wu BL. Mutations in HFM1 in recessive primary ovarian insufficiency. N Engl J Med. 2014;370(10):972-4.

19. Pu D, Wang C, Cao J, Shen Y, Wu BL, Liu J, Wu J. Association analysis between HFM1 variation and primary ovarian insufficiency in Chinese women. Clin Genet. 2016;89:597-602.

20. Zhe J, Chen S, Chen X, Liu Y, Li Y, Zhou X, Zhang J. A novel heterozygous splice-altering mutation in HFM1 may be a cause of premature ovarian insufficiency. J Ovarian Res. 2019;12(1):61.

21. Wang J, Zhang $W$, Jiang $H$, Wu BL. Primary ovarian insufficiency C: mutations in HFM1 in recessive primary ovarian insufficiency. $N$ Engl J Med. 2014;370(10):972-4.

22. Wortham NC, Proud CG. elF2B: recent structural and functional insights into a key regulator of translation. Biochem Soc Trans. 2015; 43(6):1234-40.

23. Tucker EJ, Grover SR, Robevska G, van den Bergen J, Hanna C, Sinclair AH. Identification of variants in pleiotropic genes causing "isolated" premature ovarian insufficiency: implications for medical practice. Eur J Hum Genet. 2018;26(9):1319-28.

24. Fogli A, Rodriguez D, Eymard-Pierre E, Bouhour F, Labauge P, Meaney BF, Zeesman S, Kaneski CR, Schiffmann R, Boespflug-Tanguy O. Ovarian failure related to eukaryotic initiation factor 2B mutations. Am J Hum Genet. 2003; 72(6):1544-50

25. Herrera-Garcia JD, Guillen-Martinez V, Creus-Fernandez C, MinguezCastellanos A, Carnero Pardo C. Epilepsy and ovarian failure: two cases of adolescent-onset ovarioleukodystrophy. Clin Neurol Neurosurg. 2018;165: 94-5.
26. Cui J, Wang L, Ren X, Zhang Y, Zhang H. LRPPRC: a multifunctional protein involved in energy metabolism and human disease. Front Physiol. 2019;10: 595.

27. Ghaddhab C, Morin C, Brunel-Guitton C, Mitchell GA, Van Vliet G, Huot C. Premature ovarian failure in French Canadian Leigh syndrome. J Pediatr. 2017:184:227-9 e221.

28. Elzaiat M, Todeschini AL, Caburet S, Veitia RA. The genetic make-up of ovarian development and function: the focus on the transcription factor FOXL2. Clin Genet. 2017;91(2):173-82.

29. Uhlenhaut $\mathrm{NH}$, Treier M. Foxl2 function in ovarian development. Mol Genet Metab. 2006;88(3):225-34.

30. De Baere $E$, Lemercier B, Christin-Maitre S, Durval D, Messiaen L, Fellous M, Veitia R. FOXL2 mutation screening in a large panel of POF patients and XX males. J Med Genet. 2002;39(8):e43.

31. Harris SE, Chand AL, Winship IM, Gersak K, Aittomaki K, Shelling AN. Identification of novel mutations in FOXL2 associated with premature ovarian failure. Mol Hum Reprod. 2002;8(8):729-33.

32. Laissue $P$, Lakhal B, Benayoun BA, Dipietromaria A, Braham R, Elghezal H, Philibert P, Saâd A, Sultan C, Fellous M, et al. Functional evidence implicating FOXL2 in non-syndromic premature ovarian failure and in the regulation of the transcription factor OSR2. J Med Genet. 2009;46(7): $455-7$.

33. Yang XW, He WB, Gong F, Li W, Li XR, Zhong CG, Lu GX, Lin G, Du J, Tan YQ. Novel FOXL2 mutations cause blepharophimosis-ptosis-epicanthus inversus syndrome with premature ovarian insufficiency. Mol Genet Genomic Med. 2018;6(2):261-7.

34. Grzechocińska B, Warzecha D, Wypchło M, Ploski R, Wielgoś M. Premature ovarian insufficiency as a variable feature of blepharophimosis, ptosis, and epicanthus inversus syndrome associated with c.223C > T p.(Leu75Phe) FOXL2 mutation: a case report. BMC Med Genet. 2019;20(1):019-0865

35. Hartford SA, Luo Y, Southard TL, Min IM, Lis JT, Schimenti JC. Minichromosome maintenance helicase paralog MCM9 is dispensible for DNA replication but functions in germ-line stem cells and tumor suppression. Proc Natl Acad Sci U S A. 2011;108(43):17702-7.

36. Wood-Trageser MA, Gurbuz F, Yatsenko SA, Jeffries EP, Kotan LD, Surti U, Ketterer DM, Matic J, Chipkin J, Jiang HY, et al. MCM9 mutations are associated with ovarian failure, short stature, and chromosomal instability. Am J Hum Genet. 2014;95(6):754-62.

37. Fauchereau F, Shalev S, Chervinsky E, Beck-Fruchter R, Legois B, Fellous M, Caburet S, Veitia RA. A non-sense MCM9 mutation in a familial case of primary ovarian insufficiency. Clin Genet. 2016;89(5):603-7.

38. Goldberg Y, Halpern N, Hubert A, Adler SN, Cohen S, Plesser-Duvdevani M Pappo O, Shaag A, Meiner V. Mutated MCM9 is associated with predisposition to hereditary mixed polyposis and colorectal cancer in addition to primary ovarian failure. Cancer Genet. 2015;208(12):621-4.

39. Guo T, Zheng Y, Li G, Zhao S, Ma J, Qin Y. Novel pathogenic mutations in minichromosome maintenance complex component 9 (MCM9) responsible for premature ovarian insufficiency. Fertil Steril. 2020;113(4):845-52.

40. Yang X, Zhang X, Jiao J, Zhang F, Pan Y, Wang Q, Chen Q, Cai B, Tang S, Zhou $Z$, et al. Rare variants in FANCA induce premature ovarian insufficiency. Hum Genet. 2019;138(11-12):1227-36.

41. Awasthi P, Foiani M, Kumar A. ATM and ATR signaling at a glance. J Cell Sci. 2015;128(23):4255-62.

42. Christin-Maitre S, Vasseur C, Portnoi MF, Bouchard P. Genes and premature ovarian failure. Mol Cell Endocrinol. 1998;145(1-2):75-80.

43. Miller ME, Chatten J. Ovarian changes in ataxia telangiectasia. Acta Paediatr Scand. 1967;56(5):559-61.

44. Barlow C, Hirotsune S, Paylor R, Liyanage M, Eckhaus M, Collins F, Shiloh Y, Crawley JN, Ried T, Tagle D, et al. Atm-deficient mice: a paradigm of ataxia telangiectasia. Cell. 1996;86(1):159-71.

45. Guevara-Aguirre J, Guevara A, Palacios I, Perez M, Procel P, Teran E. GH and GHR signaling in human disease. Growth Hormon IGF Res. 2018;38:34-8.

46. Zhou Y, Xu BC, Maheshwari HG, He L, Reed M, Lozykowski M, Okada S, Cataldo L, Coschigamo K, Wagner TE, et al. A mammalian model for Laron syndrome produced by targeted disruption of the mouse growth hormone receptor/binding protein gene (the Laron mouse). Proc Natl Acad Sci U S A. 1997:94(24):13215-20

47. Chen B, Li L, Wang J, Li T, Pan H, Liu B, Zhou Y, Cao Y, Wang B. Consanguineous familial study revealed biallelic FIGLA mutation associated with premature ovarian insufficiency. J Ovarian Res. 2018;11(1):48. 
48. Heddar A, Dessen P, Flatters D, Misrahi M. Novel STAG3 mutations in a Caucasian family with primary ovarian insufficiency. Mol Gen Genomics. 2019;294(6):1527-34.

49. Zhao M, Feng F, Chu C, Yue W, Li L. A novel EIF4ENIF1 mutation associated with a diminished ovarian reserve and premature ovarian insufficiency identified by whole-exome sequencing. J Ovarian Res. 2019:12(1):119.

50. Renault L, Patino LC, Magnin F, Delemer B, Young J, Laissue P, Binart N, Beau I. BMPR1A and BMPR1B missense mutations cause primary ovarian insufficiency. J Clin Endocrinol Metab. 2020;105(4):e1449-57.

\section{Publisher's Note}

Springer Nature remains neutral with regard to jurisdictional claims in published maps and institutional affiliations.

Ready to submit your research? Choose BMC and benefit from:

- fast, convenient online submission

- thorough peer review by experienced researchers in your field

- rapid publication on acceptance

- support for research data, including large and complex data types

- gold Open Access which fosters wider collaboration and increased citations

- maximum visibility for your research: over $100 \mathrm{M}$ website views per year

At $\mathrm{BMC}$, research is always in progress.

Learn more biomedcentral.com/submissions 